\section{Changes in pulmonary function in systemic sclerosis}

Sir,

Abramson et al. have recently presented a follow-up study of the pulmonary function in 66 cases with systemic sclerosis (SSc). ' We have also performed a follow-up of spirometric function study in 52 patients with SSc by Pulmostar (Fenyves-Gut, Basel, Switzerland) volumestable equipment. ${ }^{2}$ The female/male ratio was $51 / 1$, and 15 patients showed symptoms of diffuse cutaneous systemic sclerosis. The mean age at the onset of disease was $38.4 \pm 8.8$ years. The second investigation followed our first pulmonary function tests by a mean of $4.2 \pm 3.8$ $(1-8)$ years.

In contrast to the geographic and genetic differences between the two patient populations, our findings, as shown in Table I, give further additional data that the majority of patients have abnormal lung function when first tested, but overall significant worsening of spirometry (including vital capacity and forced expiratory volume in one second $\left(\mathrm{FEV}_{1}\right)$ ) is not characteristic of the great majority of patients with SSc. The decrease in the vital capacity was not significant when compared to the values to the age- and sex-matched standards (Table I).

\section{László Czirják Erzsébet Szolnoki \\ Zoltán Nagy \\ Gyula Szegedi \\ 3rd Department of Medicine, University Medical School of Debrecen, Debrecen 4004, Hungary.}

\section{References}

1. Abramson, M.J., Barnett, A.J., Litteljohn, G.O., Smith, M.M. \& Hall, S. Lung function abnormalities and decline of spirometry in scleroderma: an overrated danger? Postgrad Med J 1991, 67: 632-637.

2. Czirják, L., Bokk, Á., Lörincz, G., Csontos, G. \& Szegedi, G. A clinical study of 61 patients with systemic sclerosis. Acta Dermato-Venereol Stockh 1989, 69: 533-536.

Table I Lung function tests in 52 patients with systemic sclerosis

First investigation Second investigation

\begin{tabular}{lcc}
\hline Mean age (years) & $44.7 \pm 9.6$ & $47.6 \pm 9.8$ \\
Vital capacity (ml) & $2496 \pm 689$ & $2393 \pm 653$ \\
Vital capacity (\%)* & $70.9 \pm 14.7$ & $71.1 \pm 15.8$ \\
FEV $_{1}(\mathrm{ml})$ & $2107 \pm 623$ & $1996 \pm 624$ \\
FEV $_{1}(\%)^{*}$ & $84.4 \pm 9.3$ & $82.8 \pm 8.5$
\end{tabular}

*Percentage of the age, body surface, and sex matched controls.

\section{Contamination of blood cultures during venepuncture: fact or myth?}

Sir,

We read with interest the paper by Shahar $e t$ al. considering the sources and prevention of contamination of blood cultures.' We were relieved to note that their results support a 'routine' (that is, brief cleansing with $70 \%$ alcohol) rather than a strict regimen of antiseptic cleansing of the venepuncture site, as the former has been our recommended practice for many years.

Only $46 \%$ of their positive blood cultures were considered to be true-positives, the remainder being deemed contaminants. The authors conclude that such contamination is usually due to laboratory handling and processing rather than skin contamination at venepuncture. However, the patient's skin represents only one possible source of extrinsic contamination. Whilst contamination in the laboratory is recognized, ${ }^{2}$ the bulk of reports of pseudobacteraemia describe contamination occurring on the ward, for example, antiseptic solutions for 'skin-prep' (Pseudomonas sp.), ${ }^{3}$ ESR bottles (coliforms) ${ }^{4}$ and house officers who were removing butterfly hub caps with their teeth (streptococci)! $!^{5}$ Contamination with Bacillus species has occurred from alcohol swabs ${ }^{6}$ and medical gloves. ${ }^{7}$ We have ourselves observed contaminated cultures caused by Bacillus spores in $70 \%$ alcohol (unpublished observation). The single most important contaminant in the study of Shahar et al. was indeed a Bacillus sp. and we wonder whether the authors excluded these sources of ward-based contamination.

A further source of contamination which the authors fail to consider is that of intrinsic contamination, that is, transient bacteraemia. This is well recognized and occurs frequently during medical and dental procedures, ${ }^{8}$ but is also provoked by activities such as brushing teeth ${ }^{9}$ and chewing hard sweets ${ }^{10}$ in up to $22 \%$ of subjects. It also occurs spontaneously; as early as 1935 Okell and Elliott ${ }^{11}$ detected streptococcal bacteraemia in $10.9 \%$ of a sample of normal adults before dental manipulation. Recent studies suggest that spontaneous bacteraemia, principally with Staphyloccocus epidermidis, is the most important cause of false-positive blood cultures, occurring in $1.7 \%$ of healthy adults. ${ }^{12} \mathrm{Zierdt}^{13}$ in the type of controlled study suggested by Shahar et al., detected spontaneous bacteraemia in $6.8 \%$ of blood donors employing a lysiscentrifugation blood culture technique.

Thus the sources of blood culture contamination are more complex than Shahar $e t$ al. considers; and we would urge vigilance at every stage from patient to laboratory to avoid this confusing phenomenon.

A.R. Bell

H.A. Ludlam

Department of Medical Microbiology, St Bartholomew's Hospital, West Smithfield London WCIA 7BE, UK. 


\section{References}

1. Shahar, E., Wohl-Gottesman, B.-S. \& Shenkman, L. Contamination of blood cultures during venepuncture: fact or myth? Postgrad Med J 1990, 66: 1053-1058.

2. Maki, D.G. Through a glass darkly: nosocomial pseudoepidemics and pseudobacteraemia. Arch Intern Med 1980, 140: $26-28$.

3. Norman, P., Gosden, P.E. \& Platt, J. Pseudobacteraemia associated with contaminated skin cleansing agent. Lancet 1986, ii: 209.

4. Ispahani, P., Lewis, M.J. \& Greaves, P.W. Pseudobacteraemia again. Lancet 1985, ii: 383.

5. Cox, R.A. Pseudobacteraemia. J Hosp Infect 1989, 14: 266.

6. Berger, S.A. Pseudobacteraemia due to contaminated alcohol swabs. J Clin Microbiol 1983, 18: 974-975.

7. York, M.K. Bacillus species pseudobacteraemia traced to gloves used in collection of blood from patients with Acquired Immunodeficiency Syndrome. J Clin Microbiol 1990, 28: 2114-2116.

8. Everett, E.D. \& Hirschmann, J.V. Transient bacteraemia and endocarditis prophylaxis. A review. Medicine 1977, 56: $61-77$.

9. Cobe, H.M. Transitory bacteraemia. Oral Surg 1954, 7: 609-615.

10. Diener, J., Schwartz, S.M., Shelanski, M. \& Steinberg, G. Bacteraemia and oral sepsis with particular reference to the possible reduction of systemic disease originating from the oral cavity. J Periodontol 1964, 35: 236-241.

11. Okell, C.C. \& Elliot, S.D. Bacteraemia and oral sepis. Lancet 1935, ii: $869-872$.

12. Wilson, W., Van Scoy, R.E. \& Washington, J.A. Incidence of bacteraemia in adults without infection. J Clin Microbiol 1975, 2: 94-95.

13. Zierdt, C.H. Evidence for transitory Staphylococcus epidermidis bacteraemia in patients and healthy humans. $J$ Clin Microbiol 1983, 17: 628-630.

\section{Third degree heart block in acromegaly}

Sir,

Intraventricular conduction defects and arrhythmias are common in acromegaly.' However, third degree heart block in acromegaly has not to our knowledge previously been reported.

A 57 year old male presented with an episode of syncope. The attack lasted a few seconds and was not associated with seizure, palpitation or chest pain. He had had hypertension for 10 years, impotence for 3 years and diabetes mellitus for a year. Physical examination revealed a large, coarse-featured man with obvious features of acromegaly. His pulse rate was $56 / \mathrm{min}$, regular in rhythm, and did not change with posture. His blood pressure was $180 / 85 \mathrm{mmHg}$ supine and $150 / 80 \mathrm{mmHg}$ on standing. Examination of the jugular venous pulse revealed irregular 'cannon' $a$ waves. The first heart sound was variable in intensity.

Electrocardiograph showed the presence of third degree heart block with wide QRS complexes and a ventricular rate of $56 / \mathrm{min}$. Serum electrolytes, calcium and magnesium levels were normal. Chest X-ray showed cardiomegaly. The skull X-ray demonstrated a large pituitary fossa with a thin floor and computed tomographic (CT) scan of the brain revealed a pituitary tumour with suprasellar extension and erosion of the sphenoid sinus. Basal growth hormone level was elevated at $23.7 \mathrm{mIU} / 1$ (normal $<7 \mathrm{mIU} / \mathrm{l}$ ). This failed to suppress during an oral glucose test using 75 g glucose. Temporary pacing was instituted shortly following admission.

Further tests performed showed no significant heart rate response to exercise, intravenous atropine or isoprenaline infusion. An echo-Doppler examination of the heart showed minimal left ventricular hypertrophy, and normal mitral, aortic and tricuspid valves. There was no myocardial calcification or echocardiographic pattern suggestive of amyloidosis. Failure to respond to exercise, atropine and isoprenaline and the wide QRS of the escape pacemaker suggest the block is infraHisian. A permanent ventricular demand pacemaker (VVI) was implanted and he subsequently had a normal paced rhythm. He then underwent an uneventful transphenoidal hypophysectomy.

It is unlikely that the third degree heart block in this patient represents a problem unrelated to his acromegaly. There was no suggestion of digitalis intoxication, myocardial infarction, calcific aortic stenosis, cardiac amyloidosis or ventricular septal defect, all of which can cause third degree heart block. Idiopathic sclerosis of the conduction system and myocarditis, known causes of third degree heart block, ${ }^{2}$ are more difficult to exclude. Myocardial biopsy was not performed. Diffuse interstitial myocardial fibrosis and myocarditis are common pathological findings in acromegalics with cardiac disease. ${ }^{3,4}$ In this patient the third degree heart block is considered secondary to diffuse interstitial fibrosis involving the conduction system.

T.T. Tan

H.B. Gangaram K. Yusoff

B.A.K. Khalid

Department of Medicine, National University of Malaysia, Jalan Raja Muda, 50300 Kuala Lumpur, Malaysia.

\section{References}

1. McGuffin, W.L., Sherman, B.M., Roth, J. et al. Acromegaly and cardiovascular disorders - A prospective study. Ann Intern Med 1974, 81: 11-18.

2. Josephson, M.E., Marchlinski, F.E. \& Buxton, A.E. The bradyarrhythmias: Disorders of sinus node function and AV conduction disturbances. In: Wilson, J.D., Braunwald, E., Isselbacher, K.J. et al. (eds) Harrison's Principles of Internal Medicine, 12th ed. McGraw-Hill, New York, 1991, pp. 902-908.

3. Lie, J.T. \& Grossman, S.J. Pathology of the heart in acromegaly: anatomic findings in 27 autopsied patients. $\mathrm{Am}$ Heart J 1980, 100: 41-52.

4. van den Heuvel, P.A.C.M.B., Elbers, H.R.J., Plokker, H.W.M. \& Bruschke, A.V.G. Myocardial involvement in acromegaly. Int J Cardiol 1984, 6: 550-553.

\section{Nesidioblastosis in adults}

Sir,

Nesidioblastosis is a rare disorder which is usually considered only as a cause of neonatal hypoglycaemia. It is characterized histologically by diffuse hyperplasia of pancreatic islets of Langerhans, with apparent budding of 